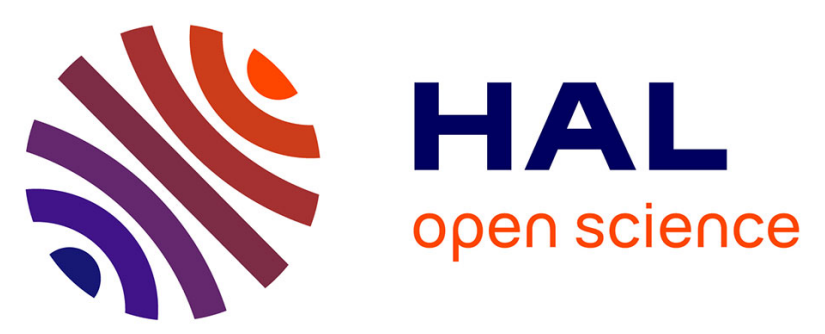

\title{
Effects of Mood States and Anxiety as Induced by the Video-Recorded Stroop Color-Word Interference Test in Simple Response Time Tasks on Reaction Time and Movement Time \\ Jean-Philippe Hainaut, Benoît Bolmont
}

\section{To cite this version:}

Jean-Philippe Hainaut, Benoît Bolmont. Effects of Mood States and Anxiety as Induced by the VideoRecorded Stroop Color-Word Interference Test in Simple Response Time Tasks on Reaction Time and Movement Time. Perceptual and Motor Skills, 2005, 101 (3), pp.721-729. 10.2466/pms.101.3.721729. hal-02012416

\section{HAL Id: hal-02012416 \\ https://hal.univ-lorraine.fr/hal-02012416}

Submitted on 8 Feb 2019

HAL is a multi-disciplinary open access archive for the deposit and dissemination of scientific research documents, whether they are published or not. The documents may come from teaching and research institutions in France or abroad, or from public or private research centers.
L'archive ouverte pluridisciplinaire HAL, est destinée au dépôt et à la diffusion de documents scientifiques de niveau recherche, publiés ou non, émanant des établissements d'enseignement et de recherche français ou étrangers, des laboratoires publics ou privés. 


\title{
Effects of mood states and anxiety as induced by the video-recorded Stroop Color-Word Interference Test in simple response time tasks on reaction time and movement time.
}

\author{
J-P. Hainaut, B. Bolmont. \\ Department of Sport Sciences, LIMBP - Emotions-Actions (EA 3940) \\ University of Metz
}

Address correspondence to Benoît Bolmont,

LIMBP (EA 3940) Emotions-Actions

Université de Metz, UFR Sciences Fondamentales Appliquées

Campus Bridoux, Avenue Général Delestraint

57070 Metz-Borny, France

e-mail (Bolmont@univ-metz.fr)

Tel/ Fax: 33387378671 / 33387378603

\section{Acknowledgements}

The authors express sincere appreciation to O. Habert and G. Bourhis for technical assistance, and the referees for their helpful comments and suggestions on an earlier version of the manuscript. 


\section{Summary}

Mood states and anxiety might alter performance in complex tasks whereas in more simple tasks such as stimulus-response, high anxiety could provoke bias in mechanisms of attention leading to better performances. We investigated the effects of anxiety, tension, and fatigue induced by the video-recorded Stroop Color-Word Interference Test, on either reaction or movement time. 61 subjects performed two response time tests (visual and auditory) in Control and Anxiogenic conditions, during which heart rate was measured. Tension and anxiety states were assessed using self-evaluated questionnaires. Our results have shown that auditory response time was improved in both reaction and movement times in Anxiogenic condition. These data suggest that the increased attention underlying anxiety and mood responses could have favored auditory response time by leading subjects to process stimuli more actively. In addition, state-anxiety and tension could have influenced muscular tension, enhancing the movement time in the auditory task.

Key Words: Reaction time, Movement time, State-Anxiety, Mood states 
A complex relationship has been highlighted between mood states, anxiety and motor performance (Jones \& Hardy, 1988; Bolmont, Thullier, \& Abraini, 2000; Wada, Sunaga, \& Nagai, 2001; Bolmont, Gangloff, Vouriot, \& Perrin, 2002; Ohno, Wada, Saitoh, Sunaga, \& Nagai, 2004). The inverted-U theory (Yerkes \& Dodson, 1908) suggests that motor performance is maximized at intermediate levels of anxiety (Martens, 1974; Raglin, 1992). However, effects of anxiety seem to be different according to the type of motor task. Adverse mood states, such as anxiety may deteriorate the subject's ability to use inputs from either the somatosensory, visual or vestibular system in static equilibrium performance (Yardley, Britton, Lear, Bird, \& Luxon, 1995; Bolmont, et al., 2002). In addition, tension, fatigue and confusion may alter latencies of neuromuscular responses to balance perturbations (Bolmont, et al., 2002). In other tasks with high information content, such as psychomotor or complex auditory and visual choice reaction time tasks, it has been suggested that state anxiety, central fatigue or confusion may produce a slowing down of the information processing and motor strategies (Jones \& Hardy, 1988; Fowler \& Lindeis, 1992; Bolmont, et al., 2000). These deficits in performance of complex tasks may be due to alterations in higher brain function (Abraini, Bouquet, Joulia, Nicolas, \& Kriem, 1998). Alternatively, anxiety would lead to better performances in visual stimulus-response tasks such as two-choice reaction tasks, which depend greatly on automatic abilities, by recruiting motivational capacities (Bolmont, et al., 2000). In fact, high anxiety provokes attentional selectivity (Azais, 1995; Peretti, 1998), which in turn would favor the information processing in binary visual choice reaction time task (Bolmont, et al., 2000). However, among studies that have investigated the relationship between mood states, anxiety and performances in reaction time, most were limited at investigating the effects of anxiety on the visuo-perceptual modalities without considering the influence of movement time (Bolmont, et al., 2000). 
The present study was designed to examine in healthy human subjects, whether anxiety and adverse mood states, such as tension and fatigue, influence positively reaction time or movement time in simple response time tasks. The induction of adverse mood changes as well as a moderate anxiety was made by the Stroop Color-Word Test with interferences, combined with video recording. This association has been shown to induce transitory psychological and physiological modifications (Tulen, Moleman, van Steenis, \& Boomsma, 1989; Silva \& Leite, 2000; Teixeira-Silva, Prado, Ribeiro, \& Leite, 2004), and is in conformity with ethical principles for research with human beings (Leite, Seabra, Sartori, \& Andreatini, 1999; Silva \& Leite, 2000; Teixeira-Silva, et al., 2004). In addition, because heart rate is associated with positive and negative mood variations (Jacob, Thayer, Manuck, Muldoon, Tamres, Williams, Ding, \& Gatsonis, 1999) and seems to be considered as a good physiological indicator of the anxiogenic response (Teixeira-Silva, et al., 2004), it was monitored throughout the experiment.

\section{METHOD}

\section{Subjects}

Participants were 61 right-handed undergraduate students ( 24 women, $19.7 \pm 2.4 \mathrm{yr}$; and 37 men, $20.6 \pm 1.5 \mathrm{yr}$ ) studying for a degree in Sport Studies at the University of Metz. They declared being free of psychiatric or neurological symptoms, and to possess normal hearing and vision. All subjects gave their full informed consent before participating in the study.

\section{Psychological and physiological measurements}

\section{State Anxiety, Tension and Fatigue}

State Anxiety was assessed using the Y1 form of the Spielberger State-Trait Anxiety Inventory (STAI; Spielberger, 1983), which is a self-evaluation questionnaire about the 
subjects' actual feelings, that consists of 20 items such as 'I feel pleasant' each scored on a 4pt. scale anchored by $1=$ 'never' and $4=$ 'very often'. Scores could range from 20 to 80 . Mood states were evaluated using two subscales taken from the Profile Of Mood States (POMS; Mc Nair, Lorr, \& Droppleman, 1971). Because the full version of the POMS is a long test, and the Anxiogenic condition provided by the Stroop color word test with interference is of short duration, the assessment of mood states was limited to Tension and Fatigue, which are main mood factors that could interact with either reaction time or movement time. These questionnaires comprised 9 adjectives for Tension such as 'nervous' or 'shaky', and 7 adjectives for Fatigue such as 'listless' or 'exhausted', each rated on a 5-pt. scale anchored by $0=$ 'not at all' and $4=$ 'extremely'. Scores could range from 0 to 36 for Tension and from 0 to 28 for Fatigue. Both STAI and POMS have shown high internal consistency and test-retest reliability. Cronbach's alphas were .90 for the STAI, .83 for the Tension subscale and .89 for the Fatigue subscale.

\section{Heart rate}

Changes in heart rate were recorded throughout the experiment using a Polar heart rate monitor (Polar Electro Inc. Medical Division, NY, USA), in order to provide physiological measurements. Heart rate means were calculated at each stage of experiment (see Fig. 1). The baseline heart rate was the mean of the heart rate over the entire first 5-min. rest period.

\section{Response time tasks}

The subjects' performances in response time were assessed using two simple tasks given only one stimulus modality (visual and auditory). While the visual stimulus consisted of a red circle appearing in the middle of the screen placed in front of the subject (nearly $60 \mathrm{~cm}$ ), the auditory stimulus was a pure tone of $1000 \mathrm{~Hz}$ presented binaurally. Although most of studies have used a great number of trials, in the present one, each task was reduced to 20 signals 
because State Anxiety induced by the Anxiogenic condition is moderate and transitory. Each signal occurred in a random delay of 1.4 to $2 \mathrm{sec}$. after positioning the finger on the home button. Subjects had to keep the finger on the home button placed at the middle of the response buttons until the stimulus occurrence. Then, they were required to press as quickly as possible the response button corresponding to the stimulus. The response buttons were located $7 \mathrm{~cm}$ to the left (auditory) or the right (visual) of the home button.

Response times were distinguished for two components: (i) reaction time, i.e. the time required to evaluate the stimulus, and to select and trigger the response, and (ii) movement time, i.e. the time required to execute the motor response. Accordingly, reaction time was measured as the time spent from the stimulus occurrence to the subject's movement onset (i.e., when the subject released the home button); movement time was evaluated as the time spent from the release of the home button to the subject's subsequent press of the response button (Jensen \& Munro, 1979). All tests were programmed with E-prime (Psychology Software Tools, Inc.) and performed on a serial response box. Performance in each response time tasks was assessed in milliseconds by calculating the median value for 20 responses.

\section{Control condition and Anxiogenic condition}

In the Anxiogenic condition, state anxiety was induced by using a Stroop color word interference test with a time limit, punishment for hesitations, and video monitoring. Each subject had to say as quickly as possible and in the sequence presented the color of the ink used to print a color name, not the color designated by the words. Hesitation in saying the color or saying the printed word instead of the ink color used to print the color name were considered as errors and were indicated with a strident sound. The task had to be performed with a 2-min, maximum. Moreover, as used in procedures that simulate public performance, the whole Anxiogenic condition was video recorded and presented on a TV screen placed in 
the visual field of the subject, in order to increase state anxiety and tension (Silva \& Leite, 2000).

In the Control condition, the subjects were given a Stroop color word-like test with no interference, which consisted of congruent color words and ink colors. Each subject had to name the ink colors that appeared in the sequence. There was no time limit in performing the test as well as no video recording.

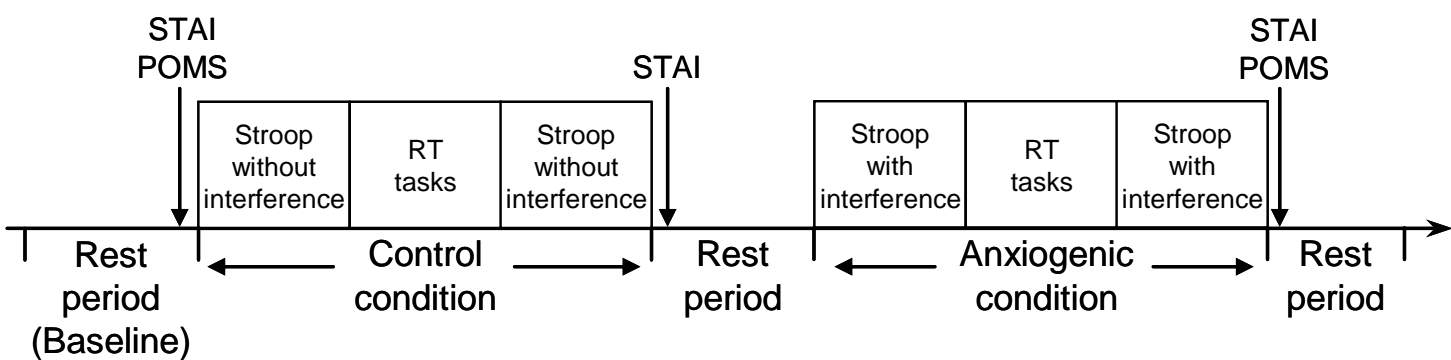

Fig. 1: procedure of the experiment. Psychometric questionnaires were realized during the first rest period (baseline) and after the Control and the Anxiogenic conditions. Heart rate was assessed throughout the experiment. All subjects $(n=61)$ performed the Control condition first and the Anxiogenic condition after. The two response time (RT) tasks were counterbalance across subjects.

\section{Test administration}

Procedure is presented in Fig.1. All subjects performed the Control condition first, and then the Anxiogenic condition. In each condition, the subjects had to (i) name the first fifty words of the Stroop test, (ii) execute the two response time tasks, and (iii) name the last fifty color words. Before the beginning of the experiment, subjects executed a training session for response time tasks. The two response time tasks were counterbalanced across subjects in order to avoid an order effect. Before, between and after each condition, the subjects were allowed to stay at rest for $5 \mathrm{~min}$.

Psychometric questionnaires, i.e., State Anxiety, Tension and Fatigue were evaluated before the beginning of the experiment and after the Anxiogenic condition. Only State Anxiety was measured after the Control condition. After each condition, questionnaires were immediately completed for mood states and anxiety. 


\section{Statistical analysis}

Heart rate means calculated at each stage of experiment were normalized using the baseline mean, and expressed in percent above or below the baseline (see Table 1). An ANOVA with repeated measures was applied to the heart rate and scores on State Anxiety across the experiment. Following a significant $F$ value, post hoc comparisons to determine pair-wise differences were performed using Student $t$-test. Scores on Tension and Fatigue obtained before experiment and after Anxiogenic condition were compared using a Student $t$ test.

Performance in reaction time and movement time were assessed by calculating the median times (msec.) for 20 signals. Auditory and visual response time tasks were processed separately. In order to find out whether the Anxiogenic condition influenced either reaction time or movement time, two-way ANOVAs were run with condition (Control, Anxiogenic) and response (reaction time, movement time) as factors.

\section{RESULTS}

Psychological parameters are presented in Table 1. Significant changes in State Anxiety were found during the course of the study $\left(F_{2,120}=22.99 ; p<.0001\right)$. Compared to the rest period, State Anxiety was significantly increased in both Control $(t=-2.79 ; p<.01)$ and Anxiogenic conditions $(t=-6.17 ; p<.0001)$. Significantly higher State Anxiety was found in Anxiogenic condition compared to the Control condition $(t=-4.62 ; p<.0001)$. Comparisons between rest period and Anxiogenic condition show a significant increase in the Tension scores of the POMS $(t=-7.89 ; p<.0001)$, but not in Fatigue. 
TABLE 1

State AnXiety, Tension, Fatigue and Heart Rate (Mean \pm SD) MEASURED IN THE FirST REST PERIOD (BASELINE), IN THE CONTROL CONDITION AND In the ANXIOGENIC CONDition. STATE ANXIETy, Tension AND FATIGUE WeRE EVALUATED By THE STAI (SPIELBERGER, 1983) AND TWO SUBSCALES OF THE POMS (MC NAIR, ET AL, 1971) RESPECTIVELY. $(\mathrm{N}=61)$

\begin{tabular}{|c|c|c|c|c|c|}
\hline & Baseline & Control condition & Anxiogenic c & condition & $F$-value $(p)$ \\
\hline State anxiety (STAI) & $32.8 \pm 8.5$ & $34.7 \pm 9.4 * *$ & $39.0 \pm 12.3$ & $* * * \mathrm{c}$ & $22.9(.0001)$ \\
\hline Tension (POMS) & $6.4 \pm 4.6$ & - & $13.1 \pm 2.4$ & $* * *$ & - \\
\hline Fatigue (POMS) & $5.2 \pm 4.2$ & - & $5.5 \pm 4.1$ & & - \\
\hline Heart rate (\%) & $100 \pm 0$ & & - & & \\
\hline Stroop (first half) & & $122.1 \pm 14.1 * * *$ & $127.4 \pm 16.2$ & $* * * \mathrm{~b}$ & \\
\hline RT tasks & & $108.8 \pm 8.3 * * *$ & $104.2 \pm 9.2$ & $* \quad \mathrm{c}$ & $106.9(.0001)$ \\
\hline Stroop (second half) & & $114.8 \pm 9.7 * * *$ & $117.3 \pm 11.4$ & $* * *$ a & \\
\hline Rest period & & $99.4 \pm 2.8$ & $99.8 \pm 3.8$ & & \\
\hline
\end{tabular}

Changes in heart rate are presented in Table 1. Significant variations were recorded across the experiment $\left(F_{8,480}=106.94 ; p<.0001\right)$. No difference was found between the three rest periods. In the Control condition, heart rate increased significantly during the Stroop test without interference (for the first fifty words: $t=-11.70 ; p<.0001$; for the last fifty words: $t=$ $-10.34 ; p<.0001)$, and the response time tasks $(t=-6.73 ; p<.0001)$ compared to the first rest period. In the Anxiogenic condition, increases in heart rate were also found during the Stroop test with interference (for the first fifty words: $t=-11.91 ; p<.0001$; for the last fifty words: $t=-10.13 ; p<.0001)$ and the response time tasks $(t=-2.42 ; p<.02)$. However, comparisons between Control and Anxiogenic conditions showed that heart rate values were significantly higher during the Stroop test with interference (the first fifty words: $t=-3.86 ; p<.001$; the last fifty words: $t=-2.42 ; p<.02$ ). In contrast, heart rate was significantly lower during the response time tasks $(t=5.47 ; p<.0001)$ in the Anxiogenic condition (cf. Table 1$)$.

Performances in auditory and visual response time tasks were analyzed separately with two-way ANOVAs (Table 2). Analysis carried out on the auditory task has shown a main effect of condition factor (Control, Anxiogenic) indicating improvement of response time performances (reaction time and movement time) in the Anxiogenic condition $\left(F_{1,60}=9.86\right.$; 
$p<.01)$. No interaction effects was found between condition (Control, Anxiogenic) and response (reaction time, movement time) factors $\left(F_{1,60}=.06\right.$; ns). Concerning the visual task, no main effect was found for the condition factor $\left(F_{1,60}=1.07\right.$; ns $)$. No interaction effects was found between condition (Control, Anxiogenic) and response (reaction time, movement time) factors $\left(F_{1,60}=.03 ; \mathrm{ns}\right)$.

It should be noted that no significant effects of order (visual then auditory task, auditory then visual task) or gender were observed on the response time tasks data or on the psychological and physiological data. Therefore, these factors were excluded in analyses.

TABLE 2

DIFFERENCES (MEAN IN MS \pm SD) OF REACTION TIME (RT) AND MOVEMENT TIME (MT) BETWEEN THE CONTROL CONDITION AND THE ANXIOGENIC CONDITION $(\mathrm{N}=61)$.

$\left.\begin{array}{ccll}\hline & & \text { Control condition } & \text { Anxiogenic condition } \\ \hline \multirow{2}{*}{\text { Visual task }} & \text { RT } & 209.0 \pm 20.2 & 207.2 \pm 23.1 \\ & \text { MT } & 128.8 \pm 30.3 & 127.6 \pm 29.7 \\ \text { Auditory task } & \text { RT } & 199.9 \pm 22.5 & 195.7 \pm 18.9 \\ & \text { MT } & 117.1 \pm 25.5 & 113.4 \pm 26.2\end{array}\right\} * *$

Significantly different from the control condition $* * p<.01$.

\section{DISCUSSION}

The purpose of this study was to exposed subjects to an Anxiogenic condition induced by the performance of a video recorded Stroop Color Word Test with interference, and assess whether anxiety and mood states could modulate positively either reaction time or movement time for simple response time tasks. The main finding of this study is that higher state anxiety and tension scores were associated with faster reaction time and movement time in an auditory but not in a visual task.

Stroop Color Word Test with interference combined with video recording have been found to activate the autonomic nervous system (Tulen, et al., 1989; Silva \& Leite, 2000; TeixeiraSilva, et al., 2004) and increase anxiety and tension (Silva \& Leite, 2000; Teixeira-Silva, et 
$a l .$, 2004). In the present study, similar results were obtained. Indeed, although state anxiety was significantly increased in the Control condition, suggesting a normal arousal response due to the experiment, the results have further shown that state anxiety was significantly higher in the Anxiogenic condition. In addition, whereas Fatigue scores remained unchanged in the Anxiogenic condition, Tension scores significantly increased. Heart rate, considered as a good physiological indicator of the anxiogenic response by Teixeira-Silva, et al. (2004) in a similar procedure, was significantly higher during the Stroop test with interference compared to the Stroop test version without interference. In agreement with previous studies, psychological and physiological responses confirm an actual anxiogenic effect.

Our results have shown a main effect of anxiety on auditory response time task suggesting that reaction time and movement time could be improved. The differences of effect on reaction time tasks could be related to the modality of the stimulus. Anxiogenic condition may increase arousal (Noteboom, Fleshner, \& Enoka, 2001), which could improve attention and lead subjects to attend actively to any incoming signal (Deutsch \& Deutsch, 1963). In addition, in agreement with a study demonstrating that heart rate could be a powerful tool for monitoring selective attention (van der Veen, van der Molen, \& Jennings, 2001), the significant slowing down of heart rate during response time tasks could further confirm that a higher selective attention is allocated in Anxiogenic condition. Thus, because in normal condition auditory stimuli are processed less actively than visual stimuli (Posner, Nissen, \& Klein, 1976), the general arousal induced by the Anxiogenic condition could have led subjects to develop more attentional resources and to process consciously auditory stimuli as well as visual stimuli.

As far as movement time for the auditory task is concerned, the lack of interaction suggests that Anxiogenic condition has a positive effect on the movement time as well as the reaction time. In line with studies showing that an optimal muscular tension tends to shorten response 
time (Spijkers, 1990; Etnyre \& Kinugasa, 2002; Kimura, Imanaka, \& Kita, 2002), results suggest that a high arousal level due to the Anxiogenic condition could have improved the muscular tension (Hoehn-Saric, Hazlett, Pourmotabbed, \& McLeod, 1997). Furthermore, a study using auditory stimulations such as loud sounds has shown that patients with generalized anxiety disorder have a significantly delayed return of forearm extensor tension to baseline following administration of a stimulus as compared with control subjects (Malmo, Shagass, \& Davis, 1950; Malmo, Malmo, \& Ditto, 2003). In agreement with these studies, we suggest that in the particular auditory stimulus case, state anxiety may maintain muscular tension and could enhance movement times for the following stimuli.

In conclusion, our results provide evidence of a significant positive effect of state anxiety and tension on response time. Performance on a simple auditory task could be improved in an Anxiogenic condition by more active stimulus processing and enhanced muscular tension. In line with the inverted-U hypothesis (Yerkes \& Dodson, 1908; Martens, 1974), we speculate that if a moderate degree of anxiety in healthy human characterized by a low initial level have a positive effect on performance, anxious patients or subjects with a state anxiety beyond an optimal point would have a dramatic decline in performance. In addition, although each sensory modality can be considered in strict isolation, in many situations people have to process simultaneously information from various modalities. Therefore, further studies are required to determine thoroughly by which mood and anxiety may influence auditory reaction time and movement time in crossmodal tasks. 


\section{REFERENCES}

Abraini, J. H., Bouquet, C., Joulia, F., Nicolas, M., \& Kriem, B. (1998) Cognitive performance during a simulated climb of mount everest: implications for brain function and central adaptive processes under chronic hypoxic stress. Pflugers Archives, European Journal of Physiology, 436(4), 553-559.

Azais, F. (1995) Cognitive experimental approach to anxiety disorders. Encephale, 21(5), 597-607.

Bolmont, B., Gangloff, P., Vouriot, A., \& Perrin, P. P. (2002) Mood states and anxiety influence abilities to maintain balance control in healthy human subjects. Neuroscience Letters, 329(1), 96-100.

Bolmont, B., Thullier, F., \& Abraini, J. H. (2000) Relationships between mood states and performances in reaction time, psychomotor ability, and mental efficiency during a 31day gradual decompression in a hypobaric chamber from sea level to $8848 \mathrm{~m}$ equivalent altitude. Physiology and Behavior, 71(5), 469-476.

Deutsch, J. A., \& Deutsch, D. (1963) Attention: some theoretical considerations. Psychological Review, 70, 80-90.

Etnyre, B., \& Kinugasa, T. (2002) Postcontraction influences on reaction time. Research Quaterly for Exercise and Sport, 73(3), 271-281.

Fowler, B., \& Lindeis, A. E. (1992) The effects of hypoxia on auditory reaction time and P300 latency. Aviation Space and Environmental Medicine, 63(11), 976-981.

Hoehn-Saric, R., Hazlett, R. L., Pourmotabbed, T., \& McLeod, D. R. (1997) Does muscle tension reflect arousal? Relationship between electromyographic and electroencephalographic recordings. Psychiatry Research, 71(1), 49-55. 
Jacob, R. G., Thayer, J. F., Manuck, S. B., Muldoon, M. F., Tamres, L. K., Williams, D. M., Ding, Y., \& Gatsonis, C. (1999) Ambulatory blood pressure responses and the circumplex model of mood: a 4-day study. Psychosomatic Medicine, 61(3), 319-333.

Jensen, A. R., \& Munro, E. (1979) Reaction time, movement time, and intelligence. Intelligence, 3, 121-126.

Jones, J. G., \& Hardy, L. (1988) The effects of anxiety upon psychomotor performance. Journal of Sports Sciences, 6(1), 59-67.

Kimura, K., Imanaka, K., \& Kita, I. (2002) The effects of different instructions for preparatory muscle tension on simple reaction time. Human Movement Science, 21(56), 947-960.

Leite, J. R., Seabra, L., Sartori, V. A., \& Andreatini, R. (1999) The video-recorded Stroop Color-Word Test as a new model of experimentally-induced anxiety. Progress in Neuropsychopharmacology and Biological Psychiatry, 23(5), 809-822.

Malmo, R. B., Malmo, H. P., \& Ditto, B. (2003) On reversible deafness, generalized anxiety disorder, and the motoric brain: a psychophysiological perspective. International Journal of Psychophysiology, 48(2), 97-113.

Malmo, R. B., Shagass, C., \& Davis, J. F. (1950) A method for the investigation of somatic response mechanisms in psychoneurosis. Science, 112(2908), 325-328.

Martens, R. (1974) Arousal and motor performance. Exercise and Sport Sciences Reviews, 2 , 155-188.

Mc Nair, D. M., Lorr, M., \& Droppleman, L. F. (1971) Manual for the Profil Of Mood States. San Diego CA: Educational and Industrial Testing Service.

Noteboom, J. T., Fleshner, M., \& Enoka, R. M. (2001) Activation of the arousal response can impair performance on a simple motor task. Journal of Applied Physiology, 91(2), $821-831$ 
Ohno, H., Wada, M., Saitoh, J., Sunaga, N., \& Nagai, M. (2004) The effect of anxiety on postural control in humans depends on visual information processing. Neuroscience Letters, 364(1), 37-39.

Peretti, C. S. (1998) Anxiety and cognition disorders. Encephale, 24(3), 256-259.

Posner, M. I., Nissen, M. J., \& Klein, R. M. (1976) Visual dominance: an informationprocessing account of its origins and significance. Psychological Review, 83(2), 157171.

Raglin, J. S. (1992) Anxiety and sport performance. Exercise and Sport Sciences Reviews, 20, 243-274.

Silva, F. T., \& Leite, J. R. (2000) Physiological modifications and increase in state anxiety in volunteers submitted to the Stroop Color-Word Interference Test: A preliminary study. Physiology and Behavior, 70(1-2), 113-118.

Spielberger, C. D. (1983) Manual for the State-Trait Anxiety Inventory (Form Y): SelfEvaluation Questionnaire. Palo Alto, CA: Consulting Psychologists Press.

Spijkers, W. A. (1990) The relation between response-specificity, S-R compatibility, foreperiod duration and muscle-tension in a target aiming task. Acta Psychologica (Amsterdam), 75(3), 261-277.

Teixeira-Silva, F., Prado, G. B., Ribeiro, L. C., \& Leite, J. R. (2004) The anxiogenic videorecorded Stroop Color-Word Test: psychological and physiological alterations and effects of diazepam. Physiology and Behavior, 82(2-3), 215-230.

Tulen, J. H., Moleman, P., van Steenis, H. G., \& Boomsma, F. (1989) Characterization of stress reactions to the Stroop Color Word Test. Pharmacology Biochemistry Behavior, 32(1), 9-15. 
van der Veen, F. M., van der Molen, M. W., \& Jennings, J. R. (2001) Selective attention and response inhibition alter phase-dependent cardiac slowing. Psychophysiology, 38(6), 896-902.

Wada, M., Sunaga, N., \& Nagai, M. (2001) Anxiety affects the postural sway of the anteroposterior axis in college students. Neuroscience Letters, 302(2-3), 157-159.

Yardley, L., Britton, J., Lear, S., Bird, J., \& Luxon, L. M. (1995) Relationship between balance system function and agoraphobic avoidance. Behavioral Research and Therapy, 33(4), 435-439.

Yerkes, R. M., \& Dodson, J. D. (1908) The relation of strength of stimulus to rapidity of habit information. Journal of Comparative Neurology and Psychology, 18, 459-482. 